\title{
Methods for the Incorporation of Carbon-11 To Generate Radiopharmaceuticals for PET Imaging**
}

\author{
Peter J. H. Scott*
}

$\mathbf{P}_{\text {o }}$ and rapidly grow radionuclides, such as carbon-11 and fluorine-18, are generated in a cyclotron and used to label small molecules. The resulting 'radiopharmaceuticals' find widespread application in the noninvasive examination of biochemical processes in living human subjects (Figure 1).

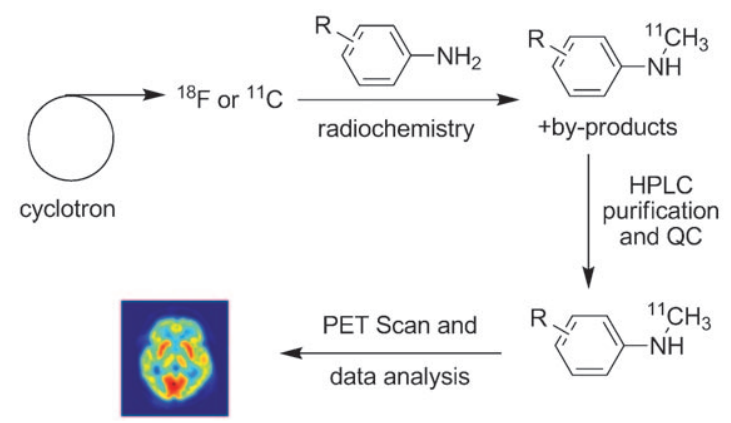

Figure 1. PET imaging: from bench to bedside.

Radiopharmaceuticals can range from the small and simple (e.g. small molecules, sugars, peptides, amino acids) to the large and complex (e.g. taxol, large peptides, proteins, antibodies) and can be custom-synthesized for applications in, for example, neurology, ${ }^{[1]}$ oncology, ${ }^{[2]}$ and cardiology. ${ }^{[3]} \mathrm{Ra}-$ diochemistry is the process by which such molecules are tagged with a radioisotope. Owing to the high levels of radiation involved, it is frequently not a trivial process. In the last two or three decades, a broad range of ingenious radiochemical reactions and automated hardware solutions have been developed to simplify the process. A detailed discussion of these developments is beyond the scope of this Highlight; however, the subject has received much attention in recent review articles in the main-stream organic chemistry

[*] Dr. P. J. H. Scott

Department of Radiology

University of Michigan Medical School

Ann Arbor, MI 48109 (USA)

Fax: (+ 1) 734-615-2557

E-mail: pjhscott@hotmail.com

$[\cdots * \cdots$ PET = positron emission tomography. carbon-11 · computed tomography · PET imaging . radiochemistry $\cdot$ radiopharmaceuticals literature ${ }^{[4]}$ most noticeably in a comprehensive article by Miller et al. ${ }^{[4 a]}$

The scope of PET imaging is perhaps endless, especially when one considers how many biochemical processes are occurring in the human body (or elsewhere in nature) at any given time. Therefore, future applications in, for example, genomics and stem-cell research are expected and eagerly anticipated. Despite this potential, and echoing the opinion of Miller et al. ${ }^{[4 a]}$ PET imaging is currently underexploited because of the limited availability of pertinent radiopharmaceuticals. Access to radiopharmaceuticals is in turn restricted by the arsenal of labeling reactions at the radiochemist's disposal. This problem is exacerbated by the fairly small number of radiochemists developing new reactions. The slow process of reaction development is often hindered further when forced into second place behind increasing clinicalproduction demands. However, the growing numbers of traditional organic chemists entering the radiochemistry arena worldwide, a trend reflected by the recent flurry of review articles, ${ }^{[4]}$ offers a promising solution to these problems. Many innovative organic chemistry techniques (e.g. solid-phase synthesis, ${ }^{[5 a-c]}$ fluorous technology, ${ }^{[5]}$ microflui$\operatorname{dics}^{[5 \mathrm{e}]}$ ) and reactions (e.g. the Huisgen cycloaddition (click chemistry), ${ }^{[6]}$ palladium-catalyzed cross-coupling reactions ${ }^{[4 a, 7]}$ ) are beginning to be adapted for radiochemical synthesis.

Carbon-11 is one of the most useful radioisotopes to work with owing to the ease with which it can be incorporated into many molecules without a significant effect on biological activity (in contrast to the detrimental effect on activity frequently encountered upon the addition of an $\left[{ }^{18} \mathrm{~F}\right]$ fluoroethyl group to a promising pharmacological scaffold). At the same time, however, competing side reactions with environmental carbon-12 sources (e.g. atmospheric ${ }^{12} \mathrm{CO}_{2}$ ) and the $20 \mathrm{~min}$ half-life make high-specific-activity radiopharmaceuticals labeled with carbon-11 some of the most synthetically challenging to prepare. The radiochemical reactions have to be very fast (must typically occur within $5 \mathrm{~min}$ ), high yielding, and clean enough that crude reaction mixtures can be purified rapidly (by semipreparative HPLC or solid-phase extraction (SPE) techniques) to provide pure radiopharmaceuticals as sterile, pyrogen-free isotonic solutions suitable for intravenous injection.

Carbon-11 is generated in the cyclotron target by a nuclear reaction with nitrogen-14 [Eq. (1)]. The resulting 
${ }^{14} \mathrm{~N}(\mathrm{p}, \alpha){ }^{11} \mathrm{C}$

(1)

carbon-11 then reacts with trace amounts of a gas added intentionally to the nitrogen-14 cyclotron target gas, either oxygen or hydrogen, to produce ${ }^{11} \mathrm{CO}_{2}$ (1) or ${ }^{11} \mathrm{CH}_{4}$ (2), respectively. These compounds can be used directly, or, much more commonly, converted into more reactive species (typically ${ }^{11} \mathrm{CH}_{3} \mathrm{I}(3)$ or ${ }^{11} \mathrm{CH}_{3} \mathrm{OTf}(4)$ ) through the use of one of a sophisticated array of automated reactions (for a selection, see Scheme 1).

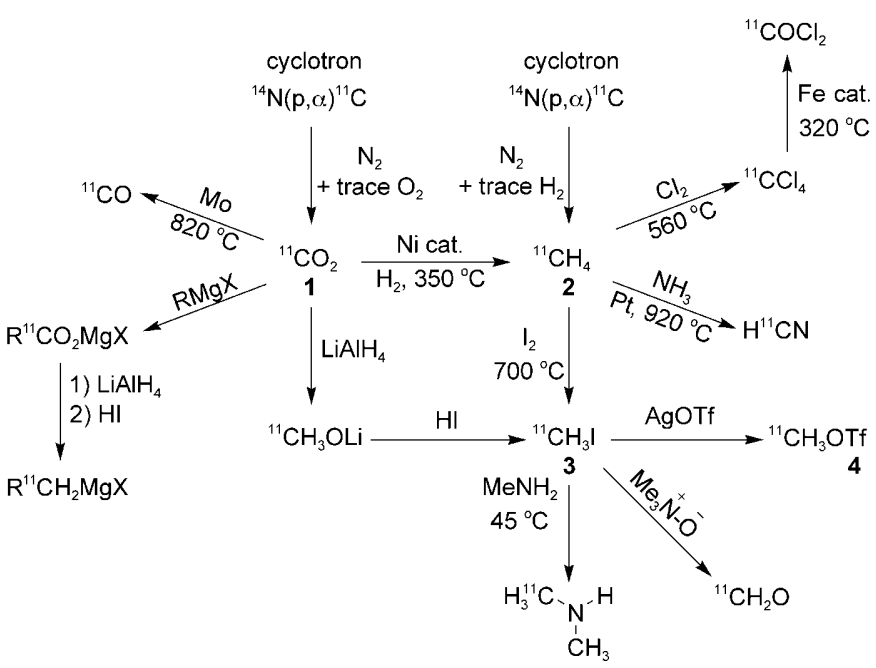

Scheme 1. Modern carbon-11 chemistry. Tf=trifluoromethanesulfonyl.

The most common reactions in modern carbon-11 chemistry involve methylation of an appropriate precursor molecule (typically an amine or phenoxide precursor) with ${ }^{11} \mathrm{CH}_{3} \mathrm{I}$ (3). In the case of less active precursors, the more reactive methylating agent ${ }^{11} \mathrm{CH}_{3} \mathrm{OTf}(4)$ can be generated by passing ${ }^{11} \mathrm{CH}_{3} \mathrm{I}$ through a column of hot silver triflate.

The use of such methylation reactions is widespread, as many pharmaceuticals contain methylamine/aniline and/or anisole pharmacophores, which makes the production of the corresponding radiopharmaceuticals a simple task. However, as the use of PET imaging in diagnostic medicine grows, requests from physicians for more complex radiopharmaceuticals are also on the increase. In many cases, simple methylation is no longer a viable labeling strategy, and alternative reactions are required. A number of groundbreaking carbon-11 reactions reported in recent years are meeting this need.

Hostetler et al. from Merck saw an opportunity to exploit the reactivity of ${ }^{11} \mathrm{CH}_{3} \mathrm{I}$ in the palladium-catalyzed Suzuki reaction (Scheme 2) ${ }^{[7]}$ The lack of $\beta$ hydrogen atoms ensures that $\beta$ elimination, a common hindrance to the use of other alkyl halides in palladium chemistry, is not possible. The optimum catalyst/base combination was found to be [Pd(dppf) $\left.\mathrm{Cl}_{2}\right] / \mathrm{K}_{3} \mathrm{PO}_{4}$, and a number of ${ }^{11} \mathrm{C}$-labeled aryl species 6 were obtained in $49-92 \%$ decay-corrected yield (DCY) from the corresponding boronic acids $\mathbf{5}$.

One drawback of ${ }^{11} \mathrm{CH}_{3} \mathrm{I}$ is that a nucleophilic precursor suitable for methylation must be first generated. More-

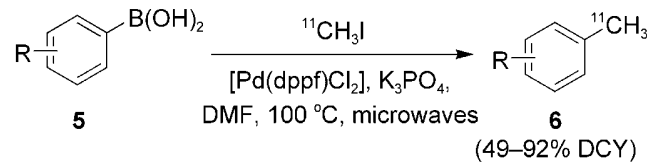

Scheme 2. Palladium-catalyzed Suzuki reaction of radiolabeled methyl iodide. $\mathrm{DMF}=N, N^{\prime}$-dimethylformamide, $\mathrm{dppf}=1,1^{\prime}$-bis (diphenylphosphanyl)ferrocene.

sensitive precursors containing other reactive functional groups can be difficult to handle and store, and are undesirable for long-term clinical-production needs. However, an interesting reversal of the reactivity profile was reported by Jacobson and Mishani. ${ }^{[8]}{ }^{11} \mathrm{CH}_{3} \mathrm{I}$ was treated with methylamine (7) to generate $\left[{ }^{11} \mathrm{C}\right]$ dimethylamine $\mathbf{8}$, which was then used to generate PET biomarkers (e.g. 9 and 10) bearing the $\left[{ }^{11} \mathrm{C}\right]$ dimethylamino functional group from the corresponding electrophilic alkyl halide precursors (Scheme 3). This reaction is expected to find widespread use in future carbon-11 chemistry.

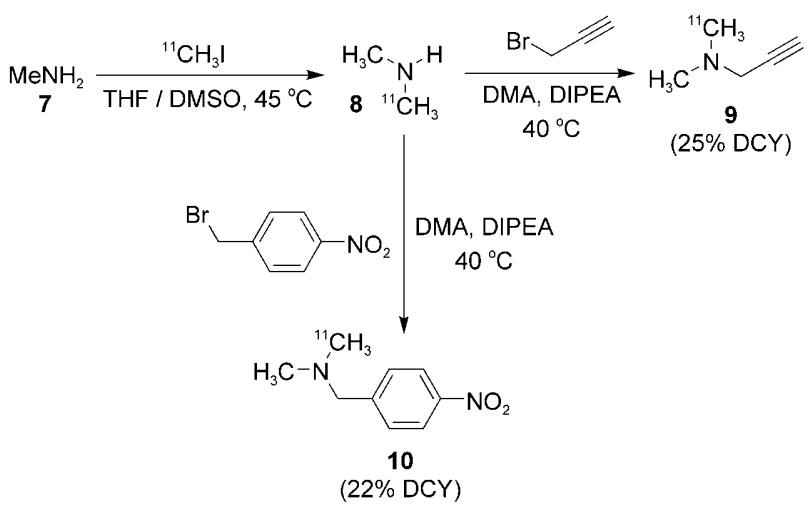

Scheme 3. Reactions of $\left[{ }^{11} \mathrm{C}\right]$ dimethylamine 8. DIPEA $=N, N^{\prime}$-diisopropylethylamine, $\mathrm{DMA}=$ dimethylamine, $\mathrm{DMSO}=$ dimethyl sulfoxide.

Hooker and co-workers have devoted much research effort to the development of novel reactions for the enhancement of carbon- 11 radiochemistry and have recently reported two useful examples. ${ }^{[9,10]}$ Like the reactions described above, the first uses ${ }^{11} \mathrm{CH}_{3} \mathrm{I}$ as a starting point. It offers an improved, very mild and rapid method of generating $\left[{ }^{11} \mathrm{C}\right]$ formaldehyde (13) (Scheme 4). The treatment of trimethylamine $N$-oxide (TMAO, 11) with ${ }^{11} \mathrm{CH}_{3} \mathrm{I}(\mathbf{3})$ provided 12, which underwent immediate decomposition into ${ }^{11} \mathrm{CH}_{2} \mathrm{O}(\mathbf{1 3})$. In a test reaction, the treatment of tryptamine (14) with ${ }^{11} \mathrm{CH}_{2} \mathrm{O}$ under acidic conditions provided labeled 2,3,4,9-tetrahydro- $1 H$ - $\beta$-carboline 15 in excellent radiochemical yield and with excellent specific activity (3.0-4.5 $\left.\mathrm{Ci} \mu \mathrm{mol}^{-1}\right)$.

The second reaction described by Hooker and co-workers is a novel one-pot method for the incorporation of ${ }^{11} \mathrm{CO}_{2}$ into carbamates (Table 1). ${ }^{[10]}$ The above reactions require the conversion of ${ }^{11} \mathrm{CO}_{2}$ into ${ }^{11} \mathrm{CH}_{3} \mathrm{I}$, followed by a labeling reaction. These two steps can take longer than $20 \mathrm{~min}$ and consume at least half of the starting radioactivity. Thus, onepot reactions in which ${ }^{11} \mathrm{CO}_{2}$ is the reactive species are in 


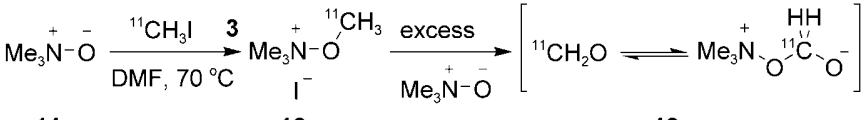

$$
\begin{aligned}
& 1112 \\
& \underbrace{\mathrm{NH}_{2}}_{\mathrm{DMF}, 70^{\circ} \mathrm{C}}
\end{aligned}
$$

Scheme 4. Reactions of $\left[{ }^{11} \mathrm{C}\right]$ formaldehyde (13). Ts = toluenesulfonyl.
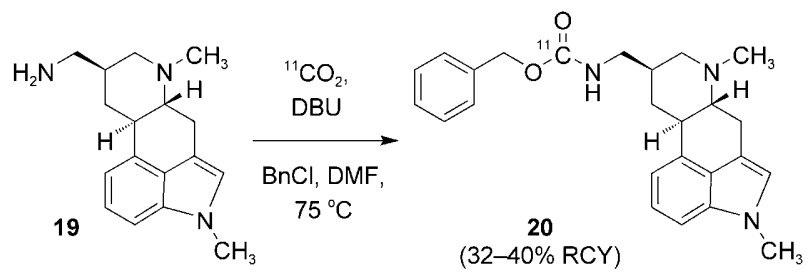

Scheme 5. Radiochemical synthesis of $\left[{ }^{11} \mathrm{C}\right]$ metergoline. $\mathrm{Bn}=$ benzyl.
Table 1: DBU-mediated incorporation of ${ }^{11} \mathrm{CO}_{2}$ into carbamates. ${ }^{[\mathrm{a}]}$

Entry

[a] Reactions were carried out with the amine $(100 \mathrm{~mm})$, the alkyl chloride, and DBU in DMF $(0.3 \mathrm{~mL})$. [b] Average RCY for two or more syntheses. [c] RCY for the reaction with the corresponding alkyl bromide.

demand. Such reactions are uncommon because of the limited number of substrates that contain suitable motifs for labeling. Nonetheless, in view of the growing demand for new radiochemical reactions, this latest study by Hooker and coworkers is timely and of great interest to the field. Initially, 1,8-diazabicyclo[5.4.0] undec-7-ene (DBU) was used to trap ${ }^{11} \mathrm{CO}_{2}$ : The authors propose the formation of 16. Compound $\mathbf{1 6}$ was treated with alkyl halides to generate intermediates $\mathbf{1 7}$, which then supplied $\left[{ }^{11} \mathrm{C}\right]$ carbamates $\mathbf{1 8}$ on treatment with an amine. The reaction yields are moderate $(\leq 77 \%)$, with scope for improvement, but do provide usable amounts of highspecific-activity $\left(5 \mathrm{Ci}^{\mathrm{m} \mathrm{mol}^{-1}}\right)$ products. Furthermore, this new labeling strategy is tolerant of water; so much so that the spiking of reactions with $10 \mathrm{mg}$ of water has a negligible effect on the reaction yield.

One significant obstacle occasionally encountered in radiochemistry is that reactions developed on simple test compounds do not translate well to complex radiopharmaceutical precursors. Thankfully, this was not the case with the method for carbamate preparation described by Hooker and co-workers. Relevance was demonstrated admirably in the production of $\left[{ }^{11} \mathrm{C}\right]$ metergoline $\mathbf{2 0}$, a PET ligand for serotonin (5HT) receptors (Scheme 5). Benzyl chloride was treated initially with the $\mathrm{DBU} /{ }^{11} \mathrm{CO}_{2}$ complex, and the resulting intermediate was quenched with the amino precursor $\mathbf{1 9}$ to provide $\left[{ }^{11} \mathrm{C}\right]$ metergoline in $32-$ $40 \%$ radiochemical yield (RCY). The designed simplicity and efficiency of this reaction should very quickly make it the method of choice for preparing related ${ }^{11} \mathrm{C}$ labeled biomarkers.

In conclusion, to meet the growing demand for novel radiopharmaceuticals in nuclear medicine, it is imperative that new labeling methods in radiochemistry continue to be developed. Many research groups worldwide are actively pursuing such endeavors with a high degree of success, as the impressive selection of new ${ }^{11} \mathrm{C}$-labeling reactions featured herein emphasizes. Such reactions in conjunction with the growing use of techniques such as solid-phase synthesis and fluorous technologies are greatly enhancing the art and science of radiopharmaceutical synthesis.

Received: March 18, 2009

Published online: June 24, 2009

[1] For reviews, see: a) A. Nordberg, Lancet Neurol. 2004, 3, 519; b) L. Cai, R. B. Innis, V. W. Pike, Curr. Med. Chem. 2007, 14, 19; c) R. M. Cohen, Mol. Imaging Biol. 2007, 9, 204; d) C. Wu, V. W. Pike, Y. Wang, Curr. Top. Dev. Biol. 2005, 70, 171; e) R. SanchezPernaute, A. L. Brownell, B. G. Jenkins, O. Isacson, Toxicol. Appl. Pharmacol. 2005, 207(2 Suppl.), 251.

[2] For reviews, see: a) J. R. Mercer, J. Pharm. Pharm. Sci. 2007, 10, 180; b) N. Oriuchi, T. Higuchi, T. Ishikita, M. Miyakubo, H. Hanaoka, Y. Iida, K. Endo, Cancer Sci. 2006, 97, 1291; c) D. Le Bars, J. Fluorine Chem. 2006, 127, 1488; d) A. M. Scott in Positron Emission Tomography: Basic Sciences (Eds.: D. L. Bailey, D. W. Townsend, P. E. Valk, M. N. Maisey), Springer, London, 2005, p. 311; e) H. Fukuda, S. Furumoto, R. Iwata, K. Kubota, Int. Congr. Ser. 2004, 1264, 158. 
[3] For reviews, see: a) F. Y. J. Keng, Ann. Acad. Med. Singapore 2004, 33, 175; b) S. Furst, MTA 1999, 14, 506.

[4] For reviews, see: a) P. W. Miller, N. J. Long, R. Vilar, A. D. Gee, Angew. Chem. 2008, 120, 9136; Angew. Chem. Int. Ed. 2008, 47, 8998; b) L. Cai, S. Lu, V. Pike, Eur. J. Org. Chem. 2008, 2843 c) R. Schirrmacher, C. Wängler, E. Schirrmacher, Mini-Rev. Org. Chem. 2007, 4, 317; d) F. Wuest, M. Berndt, T. Kniess, Ernst Schering Res. Found. Workshop 2007, 64, 183; e) B. Långström, O. Itsenko, O. Rahman, J. Labelled Compd. Radiopharm. 2007, 50, 794; f) G. Antonin, B. Långström in Positron Emission Tomography: Basic Sciences (Eds.: D. L. Bailey, D. W. Townsend, P. E. Valk, M. N. Maisey), Springer, London, 2005, p. 223

[5] a) For a recent review, see: B. G. Hockley, P. J. H. Scott, M. R. Kilbourn in Linker Strategies in Solid-Phase Organic Synthesis (Ed.: P. J. H. Scott), Wiley, Chichester, 2009, in press; b) L. J. Brown, D. R. Bouvet, S. Champion, A. M. Gibson, Y. Hu, A. Jackson, I. Khan, N. Ma, N. Millot, H. Wadsworth, R. C. D. Brown, Angew. Chem. 2007, 119, 959; Angew. Chem. Int. Ed. 2007, 46, 941; c) J. Marik, S. H. Hausner, L. A. Fix, M. K.
Gagnon, J. L. Sutcliffe, Bioconjugate Chem. 2006, 17, 1017; d) R. Bejot, T. Fowler, L. Carroll, S. Boldon, J. E. Moore, J. Declerck, V. Gouverneur, Angew. Chem. 2009, 121, 594; Angew. Chem. Int. Ed. 2009, 48, 586; e) H. Audrain, Angew. Chem. 2007, 119, 1802; Angew. Chem. Int. Ed. 2007, 46, 1772.

[6] a) For a recent review, see: C. Mamat, T. Ramenda, F. R. Wuest, Mini-Rev. Org. Chem. 2009, 6, 21; b) M. Glaser, E. Årstad, Bioconjugate Chem. 2007, 18, 989; c) J. Marik, J. L. Sutcliffe, Tetrahedron Lett. 2006, 47, 6681.

[7] E. D. Hostetler, G. E. Terry, H. D. Burns, J. Labelled Compd. Radiopharm. 2005, 48, 629.

[8] O. Jacobson, E. Mishani, Appl. Radiat. Isot. 2008, 66, 188.

[9] J. M. Hooker, M. Schönberger, H. Schieferstein, J. S. Fowler, Angew. Chem. 2008, 120, 6078; Angew. Chem. Int. Ed. 2008, 47, 5989.

[10] J. M. Hooker, A. T. Reibel, S. M. Hill, M. J. Schueller, J. S. Fowler, Angew. Chem. 2009, 121, 3534; Angew. Chem. Int. Ed. 2009, $48,3482$. 